\title{
Dynamic routing modeling for flash flood forecast in river system
}

\author{
Wen-Cheng Liu $\cdot$ Wei-Bo Chen $\cdot$ Ming-Hsi Hsu $\cdot$ Jin-Cheng Fu
}

Received: 2 October 2007 / Accepted: 7 April 2009

(C) Springer Science+Business Media B.V. 2009

\begin{abstract}
A real-time flood-forecasting method coupled with the one-dimensional unsteady flow model was developed for the Danshuei River system in northern Taiwan. Based on the flow at current time, the flow at new time is calculated to provide the water stage forecasting during typhoons. Data, from two typhoons in 2000: Bilis and Nari, were used to validate and evaluate the model capability. First, the developed model was applied to validate and evaluate with and without discharge corrections at the Hsin-Hai Bridge in Tahan Stream, Chung-Cheng Bridge in Hsintien Stream, and Sir-Ho Bridge in the Keelung River. The results indicate that the calculated water stage profiles approach the observed data. Moreover, the water stage forecasting hydrograph with discharge correction is close to the observed water stage hydrograph and yields a better prediction than that without discharge correction. The model was then used to quantify the difference in prediction between different methods of real-time water stage correction. The model results reveal that water stages using the 1-6 h forecast with real-time stage correction exhibits the best lead times. The accuracy for $1-3 \mathrm{~h}$ lead time is higher than that for $4-6 \mathrm{~h}$ lead time, suggesting that the flash flood forecast in the river system is reasonably accurate for $1-3 \mathrm{~h}$ lead time only. The method developed is effective for flash flood forecasting and can be adopted for flood forecasting in complicated river systems.
\end{abstract}

Keywords Flood forecasting - Dynamic flood routing - Discharge correction · Water stage correction · Leading time · Dansheui River system

W.-C. Liu $(\bowtie)$

Department of Civil and Disaster Prevention Engineering, National United University, Miao-Li 36003, Taiwan

e-mail: wcliu@nuu.edu.tw

W.-B. Chen · M.-H. Hsu

Department of Bioenvironmental Systems Engineering, National Taiwan University, Taipei 10617, Taiwan

J.-C. Fu

National Science and Technology Center for Disaster Reduction, Taipei County 23143, Taiwan 


\section{Introduction}

Many countries in the Asian Pacific region experience frequent and devastating floods. Damage from frequent flooding has been staggering, making floods the most destructive, natural hazards in the region. The frequency of floods is increasing because of deforestation, poor land drainage, expanding agriculture, and urbanization. All these activities contribute to increased runoff and more significant flood peaks. Thus, accurate spatial and temporal information of a flood event is crucial to the design of structural and nonstructural measures for flood prevention and disaster mitigation.

With the rapid advancement of computer power in the recent years, dynamics flood routing models have been widely used for flood forecasting (Nguyen and Kawano 1995; Lamberti and Pilati 1996; Saavedra et al. 2003; Madsen and Skotner 2005; Kaya et al. 2005; Hsu et al. 2006; Mu and Zhang 2007). Accurate and reliable flow forecasting forms an important basis for efficient real-time river management, including flood control, flood warning, and river regulation. The core of a state-of-the-art operational flow forecasting system is a hydrological and hydrodynamic simulation model that uses information of the current state of the river basin together with the model forecasting (precipitation and model boundaries) to provide forecasts of the water stages and discharges in the river system. The forecast errors of such a system are related to the current state of the river basin initialized by the simulation model, errors in the model forcing forecasts, and errors related to the simulation model itself. In order to improve the estimate of the initial state of the system and to reduce the simulated errors in the forecasted period, a data assimilation procedure is often implemented in the forecasted system. In general, data assimilation is a feedback process where the model prediction is conditioned to the observations of the river system (water stages and discharge measurements).

Data assimilation procedures can be classified according to the variables that are modified in the data assimilation feedback process, i.e., input variables (model forcing), model states, model parameters, and output variables (WMO 1992). Updating of output variables is also known as error correction. In this case, an error correction forecast model is based on the observed model residual, and this model is then superimposed on the simulation model. Error correction procedures have been applied for updating: runoff in the conceptual rainfall-runoff models (Refsgaard 1997; Lee and Singh 1999; Madsen et al. 2000; Khu et al. 2001; Hartnack and Madsen 2001; Madsen et al. 2003), velocities at specific locations (Babovic et al. 2001), and water stages in the hydrodynamic model (Shiiba et al. 2000; Madsen and Skotner 2005; Hsu et al. 2006; Mu and Zhang 2007). Error correction techniques are generally very cost-effective, and hence efficient for data assimilation in the river system.

In this study, a dynamic routing model for flood forecasting was developed and evaluated with and without real-time discharge corrections with improvement from different methods of water stage correction to calculate the forecasted water stage in the Danshuei River system in northern Taiwan. Error analyses were also provided to evaluate the realtime forecasting results in water stage for the key locations in the river system.

\section{Model description for flood forecasting system}

The flood routing model is based on the dynamic wave theory of the Saint-Venant equations which consist of the $1 \mathrm{D}$ continuity and momentum equations: 


$$
\begin{gathered}
\frac{\partial A}{\partial t}+\frac{\partial Q}{\partial x}-q_{1}+q_{2}=0 \\
\frac{\partial Q}{\partial t}+\frac{\partial}{\partial x}\left(\frac{Q^{2}}{A}\right)-g A\left(S 0-\frac{\partial Y}{\partial x}-S \mathrm{f}\right)-q_{1} V_{1}+q_{2}\left(\frac{Q}{A}\right)=0
\end{gathered}
$$

where $A$ is the cross-sectional area, $Y$ is the water depth, $Q$ is the discharge, $q_{1}$ is the lateral inflow per unit channel length, $q_{2}$ is the lateral outgoing overflow per unit channel length, $S_{0}$ is the channel bottom slope, $S_{\mathrm{f}}$ is the friction slope, $V_{1}$ is the longitudinal velocity component of the lateral inflow, $g$ is the gravitational acceleration, $t$ is the time, and $x$ is the distance along the channel. Since the cross-sectional area can be written as a function of water depth, only two flow variables, $Q$ and $Y$, have to be solved in Eqs. 1 and 2.

Equations 1 and 2 are solved numerically, given the initial and boundary conditions. The four-point implicit finite-difference approximation scheme (Preissman 1961; Amein and Fang 1970) was used in this study. In spatial discretization, the two adjoining cross sections can be incorporated into two equations with four unknowns of flow variables at the advanced time

$$
\begin{aligned}
& C_{\ell}\left(Q_{\ell+1}^{t+1}, Y_{\ell+1}^{t+1}, Q_{\ell}^{t+1}, Y_{\ell}^{t+1}, Q_{\ell+1}^{t}, Y_{\ell+1}^{t}, Q_{\ell}^{t}, Y_{\ell}^{t}\right)=0 . \\
& M_{\ell}\left(Q_{\ell+1}^{t+1}, Y_{\ell+1}^{t+1}, Q_{\ell}^{t+1}, Y_{\ell}^{t+1}, Q_{\ell+1}^{t}, Y_{\ell+1}^{t}, Q_{\ell}^{t}, Y_{\ell}^{t}\right)=0,
\end{aligned}
$$

where $C_{\ell}$ and $M_{\ell}$ are the discretized continuity and momentum equations between the $\ell$-th and the $(\ell+1)$-th cross sections, respectively. The subscript $\ell$ denotes the cross-sectional index, for $1,2, \ldots, L$, numbering from upstream to downstream and $t$ and $(t+1)$ are the flow variables at the present and advanced times, respectively.

For a river system with $L$ cross sections, a system of $(2 L-2)$ equations with $2 L$ unknown flow variables results. The deficiency in the number of equations is supplemented with boundary conditions to solve the unknowns.

Due to non-linearity, Eqs. 3 and 4 are solved with an iterative procedure-the NewtonRaphson method:

$$
\begin{aligned}
\left(Q_{\ell}^{t+1}\right)_{m+1} & =\left(Q_{\ell}^{t+1}\right)_{m}+\left(\delta Q_{\ell}^{t+1}\right)_{m} \\
\left(Y_{\ell}^{t+1}\right)_{m+1} & =\left(Y_{\ell}^{t+1}\right)_{m}+\left(\delta Y_{\ell}^{t+1}\right)_{m}
\end{aligned}
$$

where $\left(Q_{\ell}^{t+1}\right)_{m+1},\left(Y_{\ell}^{t+1}\right)_{m+1}$, and $\left(Q_{\ell}^{t+1}\right)_{m},\left(Y_{\ell}^{t+1}\right)_{m}$ are the flow variables at the advanced time for $(m+1)$ th and $m$ th iterations, respectively, $\left(\delta Q_{\ell}^{t+1}\right)_{m}$ and $\left(\delta Y_{\ell}^{t+1}\right)_{m}$ are current increments of flow variables for the $m$ th iteration, $m$ iterative index. For $m=1$, the initial trials of flow variables at the new time can be set to the flow variables at the current time, $\left(Q_{\ell}^{t+1}\right)_{1}=Q_{\ell}^{t}$ and $\left(Y_{\ell}^{t+1}\right)_{1}=Y_{\ell}^{t}$.

In each step of iterations, the current increments of flow variables are solved by a set of equations to adapt the flow variables at the advanced time.

$$
a_{i, j} \cdot \delta_{j}=s_{i}
$$

where $i=1,2, \ldots 2 N, j=1,2, \ldots, 2 N$. $\delta_{j}$ is the current increment of flow variables. $\delta Q$ or $\delta Y$, arranged by the order of the cross-sectional index, $a_{i j}$ is the Jacobian matrix coefficient derived from the flow variable derivation of the momentum and continuity equations, $s_{i}$ is the residual calculated from Eqs. 3 and 4. These coefficients of $a_{i, j}$ and $s_{i}$ depend not only on the flow variables at current time but also on that of the current iteration. The Gaussian elimination method with pivoting was used to solve these simultaneous equations. It is 
clear that computation of flood routing proceeds by solving Eq. 6 for each time step without any corrections.

The concept of flash flood forecasting performance uses the current-time flow to predict the new-time flow and provides the flood warning information. Based on the current-time flow, the new-time flow can be calculated to provide the water stage forecasting during the typhoon events. The following methods were adopted in the computation:

1. without water stage correction;

2. water stage correction depended on distance, real-time observed water stages as the internal boundary conditions to adjust the present-time flow;

3. water stage correction with distance and real-time observed values at gauge stations were adopted to investigate and evaluate the results of flash flood forecasting.

\section{Application}

\subsection{Case study site}

The model was applied to the Danshuei River system located in northern Taiwan (Fig. 1). It has three major tributaries: Tahan Stream, Hsintien Stream, and Keelung River, and its watershed has a population of over six millions (Liu et al. 2001a, b). The Erchung Floodway, built near the confluence of Tahan Stream and Hsintien Stream in 1984, is used to divert the flood flows. The Danshuei watershed area is $2,726 \mathrm{~km}^{2}$ with a mean annual precipitation of $3,001 \mathrm{~mm}$. The total channel length is $327.6 \mathrm{~km}$, and the channel slope ranges from 0.015 to 0.0027 . The peak discharge of a 200 -year flood is $25,000 \mathrm{~m}^{3} / \mathrm{s}$. Freshwater discharges at the upstream tidal limit of the Tahan Stream, Hsintien Stream, and Keelung River are $62.1,72.7$, and $26.1 \mathrm{~m}^{3} / \mathrm{s}$, respectively. The mean tide at the

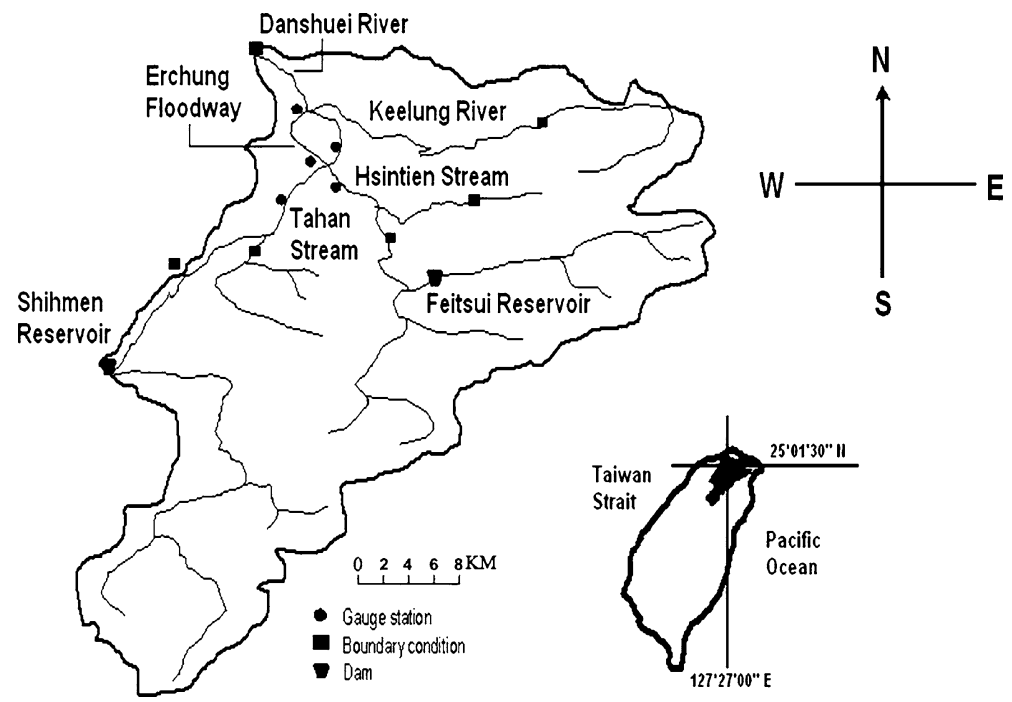

Fig. 1 Map of the Danshuei River system and basin 
Danshuei River mouth is $2.21 \mathrm{~m}$. The downstream reaches of all the three tributaries are affected by tides (Liu et al. 2004, 2007).

Steep land slopes and short river channels render very short time of floodwater convergence, approximately 3-6 h. Flood inundation in the lowland of the Taipie metropolitan area often occurs, causing significant property damage, when typhoons or rainstorms strike.

\subsection{Model setup}

In this study, the model transects were established with the measured cross-sectional profiles at about $0.5 \mathrm{~km}$ interval along the river. The model transects in the computational domain that includes 211 transects covered 11 river reaches (shown in Table 1). The arranged river reaches is also shown in Fig. 2. Since the channel shapes are wide and shallow, the effects of two-stage channels (main channel and floodplains) (Ackers 1992) are not obvious in the Danshuei River system. Thus, the same Manning coefficient $n$ for the main channel and floodplain is used in the study. The upstream boundaries are specified at the Yan-Shan Weir (Tahan Stream), Gan-Cheng Bridge (San-Xia Stream, a tributary of the Tahan Stream), Bi-Tan Bridge (Hsintien Stream), Bao Bridge (Jing-Mei Stream, a tributary of the Hsintien Stream), and Wu-Du (Keelung River). The downstream boundary is located at the Danshuei River mouth. The upstream and downstream boundaries are shown in Fig. 2. The boundary conditions of the dynamic flood routing model at the upstream watershed are the discharges and the tide stages at the river mouth. The tide stages are the sum of the astronomical tide, which is derived from the harmonic analyses, and the meteorological tide, which is the difference between the observed and the astronomical tidal stages (Yen et al. 1998). The meteorological typhoon quantitative precipitation forecast model supplied the rainfall data to calculate the discharges at upstream boundaries using the runoff forecasting model (Lee et al. 2000; Lee and Hsu 2001; Wang and Hsieh 2000). The discharges from upstream boundary conditions for the real-time forecasting results (including present time and 1-6 h ahead of forecast) are depicted in Fig. 2.

\section{Model results}

Manning's $n$ is the key parameter affecting the computed stages of a dynamic routing model. A trial-and-error procedure was usually applied to validate the Manning $n$. In this study, data from the Bilis and Nari typhoon events in 2000 were used to validate the Manning's $n$ and to demonstrate the water stage forecasting capability of the model.

Table 1 Cross-sectional number of river reach and Manning $n$ used in the computational domain

\begin{tabular}{|c|c|c|c|c|c|c|}
\hline River reach no. & 1 & 2 & 3 & 4 & 5 & 6 \\
\hline $\begin{array}{l}\text { Number of cross } \\
\text { sections }\end{array}$ & 2 & 2 & 28 & 8 & 13 & 22 \\
\hline Manning $n$ & 0.039 & 0.039 & $0.033-0.039$ & $0.033-0.040$ & $0.035-0.045$ & $0.030-0.035$ \\
\hline River reach no. & 7 & 8 & 9 & 10 & 11 & n.e. \\
\hline $\begin{array}{l}\text { Number of cross } \\
\text { sections }\end{array}$ & 23 & 9 & 3 & 87 & 14 & n.e. \\
\hline Manning $n$ & $0.022-0.027$ & $0.022-0.030$ & 0.025 & $0.019-0.090$ & $0.023-0.028$ & n.e. \\
\hline
\end{tabular}

Note: n.e. $=$ no entry 


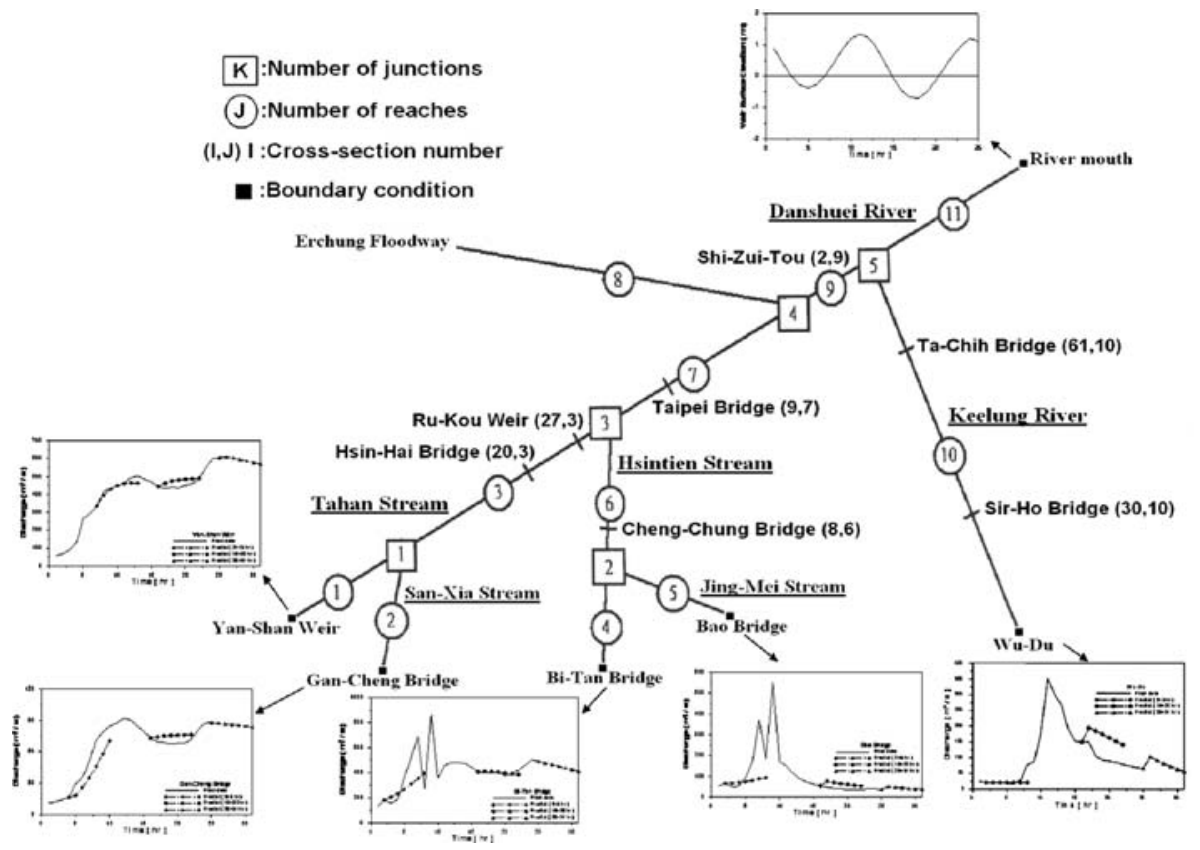

Fig. 2 Danshuei River system layout for model simulation and boundary conditions

\subsection{With and without discharge corrections}

Dynamic routing modeling for flash flood forecasting was used to validate the Manning $n$ and to evaluate the effects with and without discharge corrections on the forecasting water stages. The upstream boundary conditions specified in the forecasting model include the current-time discharge and lead-time forecasting data (see Fig. 2). The current-time discharges at upstream boundaries were determined from the real-time observed runoff hydrographs at the gauge stations. The 6-h leading runoff forecasting data were obtained from rainfall forecasting and rainfall-runoff models, which were described in a technical report of the Taiwan Water Resources agency (Hsu et al. 2000; Lee and Hsu 2001). Since the Danshuei River is a tidal river, the current-time observed tidal stage at the Danshuei River mouth can be obtained and served as the downstream boundary condition. In addition, the summation of the astronomical tide and the meteorological tide at the Dasnhuei River mouth was specified as the 6-h leading boundary condition (Hsu et al. 2000).

With the discharge correction, the general formula for water stage-discharge rating curves at the Hsin-Hai Bridge (Tahan Stream), Chung-Cheng Bridge (Hsintien Stream), and Sir-Ho Bridge (Keelung River) were adopted as follows:

$$
\begin{array}{r}
R Q=a \cdot\left(Y_{\mathrm{E}}+b\right)^{c} \\
F=R Q /|Q|
\end{array}
$$

where $Y_{\mathrm{E}}$ is the observed water stage, $R Q$ is the estimated discharge through rating curve, $a, b$, and $c$ are the constants, $|Q|$ is the absolute value of calculated discharge through the model, and $F$ is the factor. The discharges at the upstream boundaries (i.e., Yan-shan Weir, Gan-Cheng Bridge, Bi-Tan Bridge, Bao Bridge, and Wu-Du, shown in Fig. 2) can be 
Table 2 Constant values for the rating curve used at Hsin-Hai Bridge, Chung-Cheng Bridge, and Sir-Ho Bridge

\begin{tabular}{llll}
\hline Location & $\begin{array}{l}\text { Hsin-Hai Bridge } \\
\text { (Tahan Stream) }\end{array}$ & $\begin{array}{l}\text { Chung-Cheng Bridge } \\
\text { (Hsintien Stream) }\end{array}$ & $\begin{array}{l}\text { Sir-Ho Bridge } \\
\text { (Keelung River) }\end{array}$ \\
\hline$a$ & 7.0 & 5.41 & 2.13 \\
$b$ & 0.0696 & 0.2659 & 1.2929 \\
$c$ & 4.2041 & 3.7659 & 2.838 \\
\hline
\end{tabular}

adjusted if the factors $(F)$ were yielded. Table 2 presents the constants $a, b$, and $c$ used in the study at the Hsin-Hai Bridge (Tahan Stream), Chung-Cheng Bridge (Hsintien Stream), and Sir-Ho Bridge (Keelung River).

The spatial variations of water surface elevation (i.e., water stage) along the Danshuei River-Tahan Stream forecasted for typhoons Bilis and Nari at 15th, 20th, and 25th $\mathrm{h}$ are presented in Fig. 3, showing with and without discharge corrections. It shows that the calculated water stage profiles approach the observed ones with and without discharge corrections. The water stage forecasting hydrographs are plotted with observed ones presented in Figs. 4 and 5 for typhoons Bilis and Nari, respectively. They present the water stage of forecasting hydrographs of the Hsin-Hai Bridge at the present time and 1-6 $\mathrm{h}$ ahead. The figures also reveal that the water stage forecasting hydrograph with discharge correction is close to the observed water stage hydrograph and yields a better prediction than that without discharge correction.

Scatter plots for point-by-point comparison of forecasted and observed water stage at the real time, 1-6 h ahead for the two typhoon events at the Hsin-Hai Bridge are presented in Fig. 6. A solid, diagonal line indicates the one-to-one correspondence. The correlation coefficient $\left(R^{2}\right)$ between observed and computed water stages are also specified in the figure. The $R^{2}$ with discharge correction at the real-time, $1-6 \mathrm{~h}$ heads are $0.97,0.98,0.97$, $0.93,0.88,0.82$, and 0.74 , respectively, and without discharge correction at the real-time, $1-6 \mathrm{~h}$ ahead are $0.88,0.89,0.90,0.90,0.88,0.85$, and 0.81 , respectively. The results reveal that forecasting water stage at real time and $1-3 \mathrm{~h}$ ahead with discharge correction exhibits the best lead times than that without correction. The forecasting water stage for $4-6 \mathrm{~h}$ ahead with and without discharge corrections are slightly different.

\subsection{Different methods for water stage correction}

In order to evaluate the accuracy and capability of dynamic routing model for flood forecasting, different methods for water stage correction were considered in the study. Since the discharge correction has been demonstrated to be better than the without discharge correction in dynamic flood modeling processes, the discharge correction was incorporated into different methods for water stage correction. The four different methods were illustrated as follows:

Method A Without water stage correction.

Method B Water stage correction depended on the distances. The calculated water stage included seven stations-Hsin-Hai Bridge (Tahan Stream), Chung-Cheng Bridge (Hsintien Stream), Ru-Kou Weir (Danshuei River), Taipei Bridge (Danshuei River), Shi-Zui-Tou (Danshuei River), Ta-Chih Bridge (Keelung River), and Sir-Ho Bridge (Keelung River) that served as the interior boundary conditions to adjust the real-time flow. 

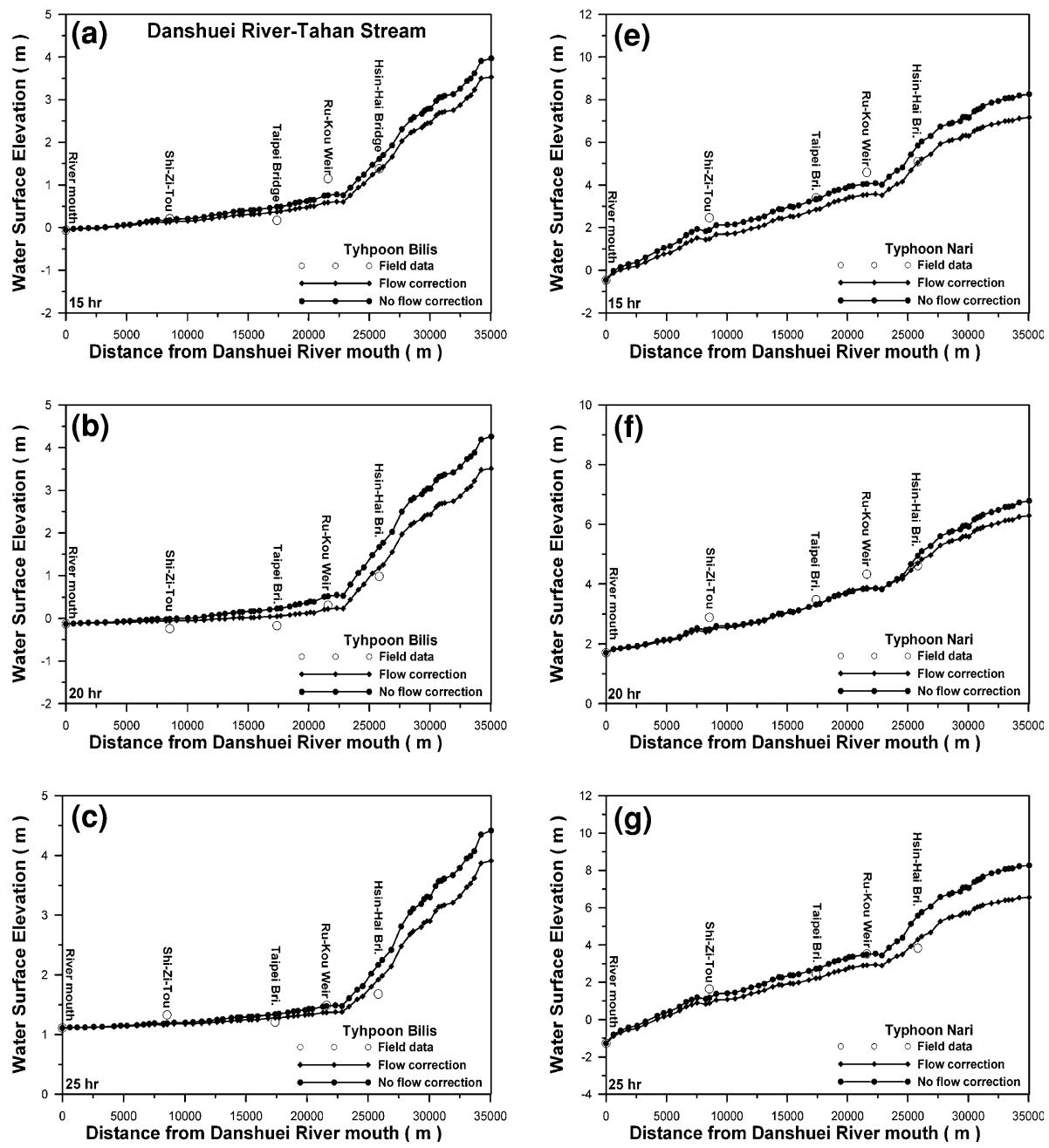

Fig. 3 Comparisons of computed and observed water stage profiles for typhoon Bilis at time: (a) 15th hour; (b) 20th hour; and (c) 25th hour, and for typhoon Nari at time: (d) 15th hour; (e) 20th hour; and (f) 25th hour in the Danshuei River-Tahan Stream

Method C Water stage correction according to observed water stages. In order to implement the real-time stage correction, Hsin-Hai Bridge, Chung-Cheng Bridge, Ru-Kou Weir, Taipei Bridge, Shi-Zui-Tou, Ta-Chih Bridge, and Sir-Ho Bridge are specified as the interior boundary conditions to adjust the real-time flow. The root-mean-square errors (RMSE) of the difference between observed and computed water stages at gauge stations were used for real-time water stage correction.

$$
\operatorname{RMSE}=\left\{\frac{1}{n}\left[\sum_{1}^{n}\left(Y_{\mathrm{o}}-Y_{\mathrm{c}}\right)^{2}\right]\right\}^{1 / 2}
$$

where $Y_{\mathrm{c}}$ is the computed water depth, $Y_{\mathrm{o}}$ is the observed water depth, and $n$ is the total number of water stage gauge stations in the river system. 

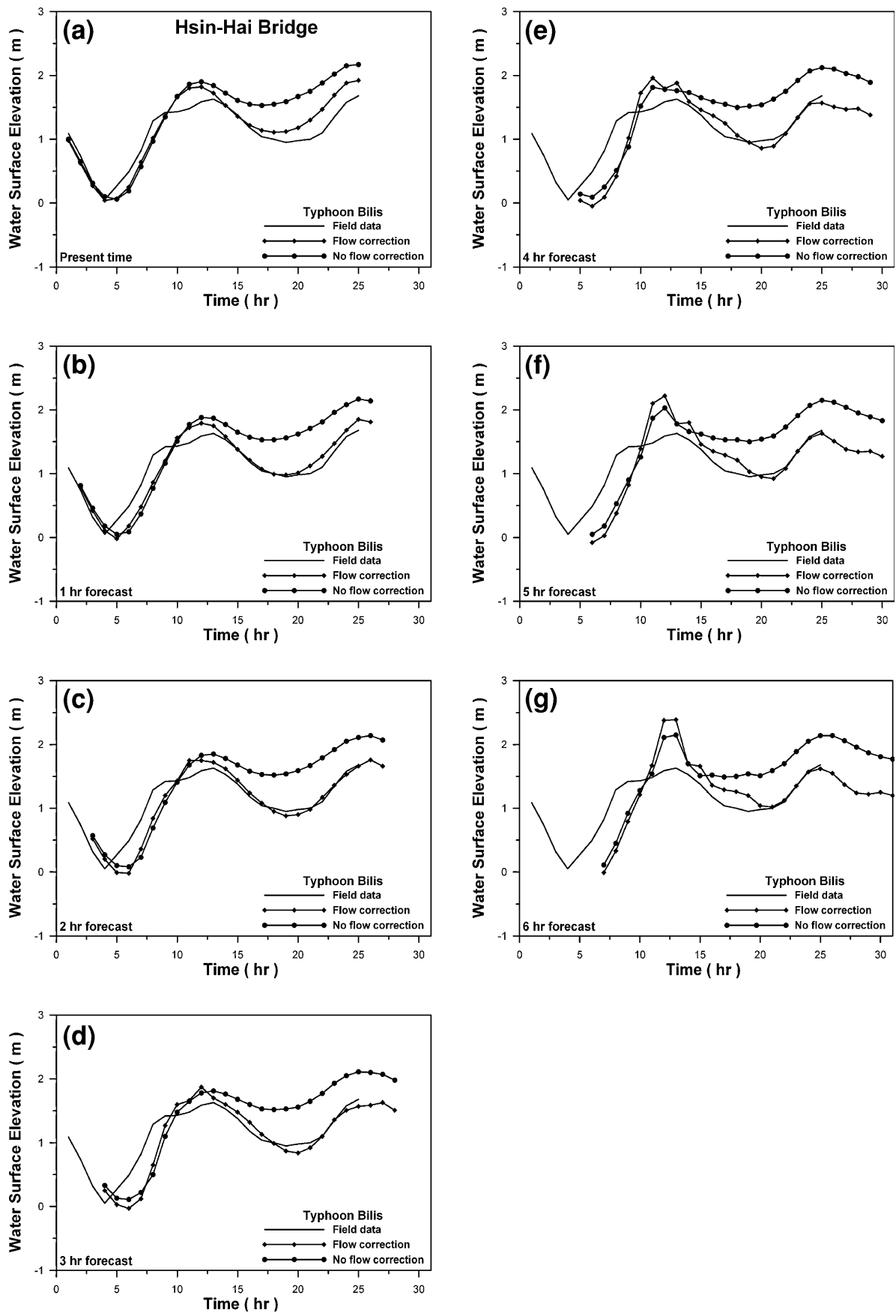

Fig. 4 a Present time and b-g 1-6 h forecasted water stage hydrographs with and without discharge corrections for typhoon Bilis at the Hsin-Hai Bridge (Tahan Stream) 

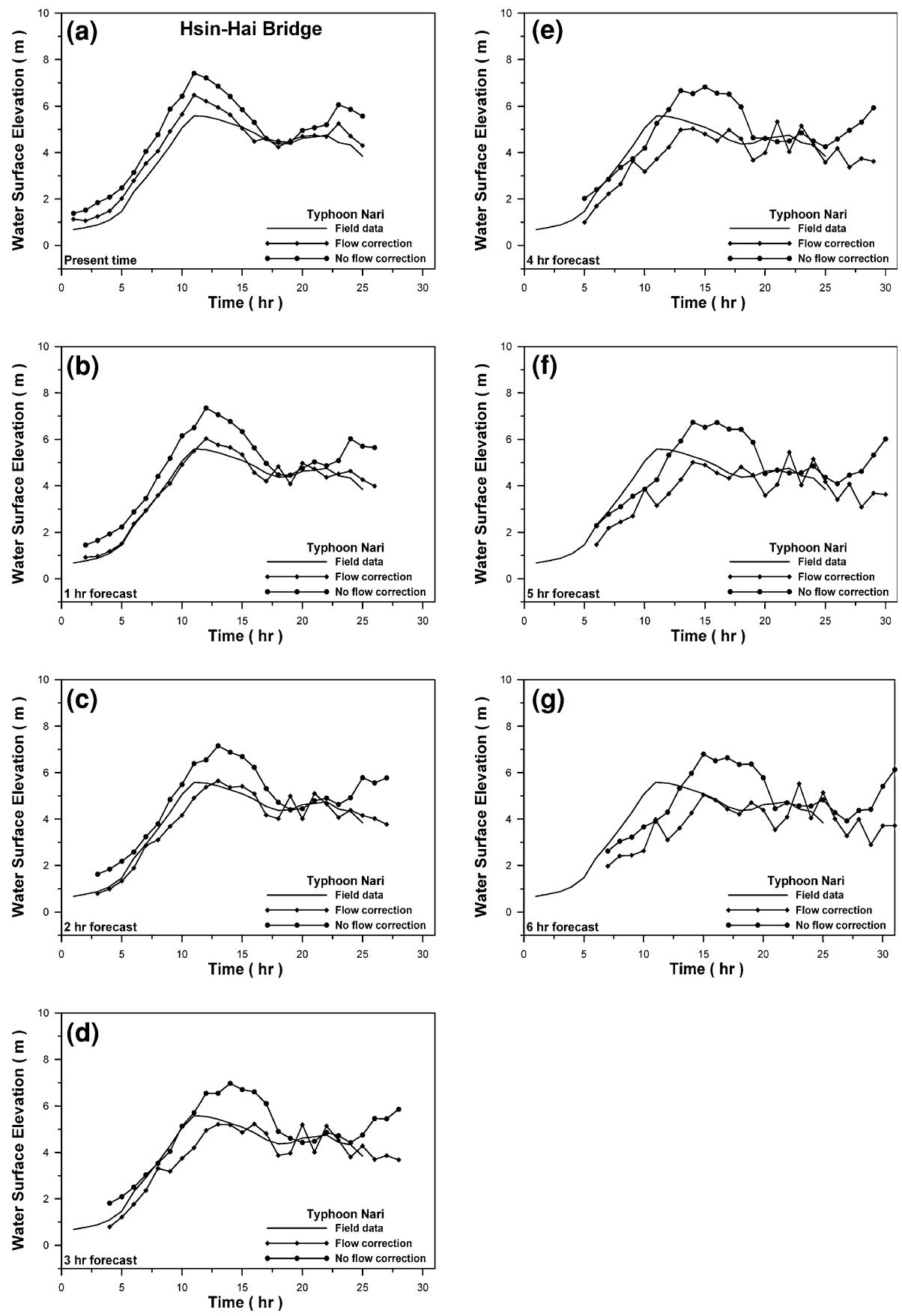

Fig. 5 a Present time and b-g 1-6 h forecasted water stage hydrographs with and without discharge corrections for typhoon Nari at the Hsin-Hai Bridge (Tahan Stream) 

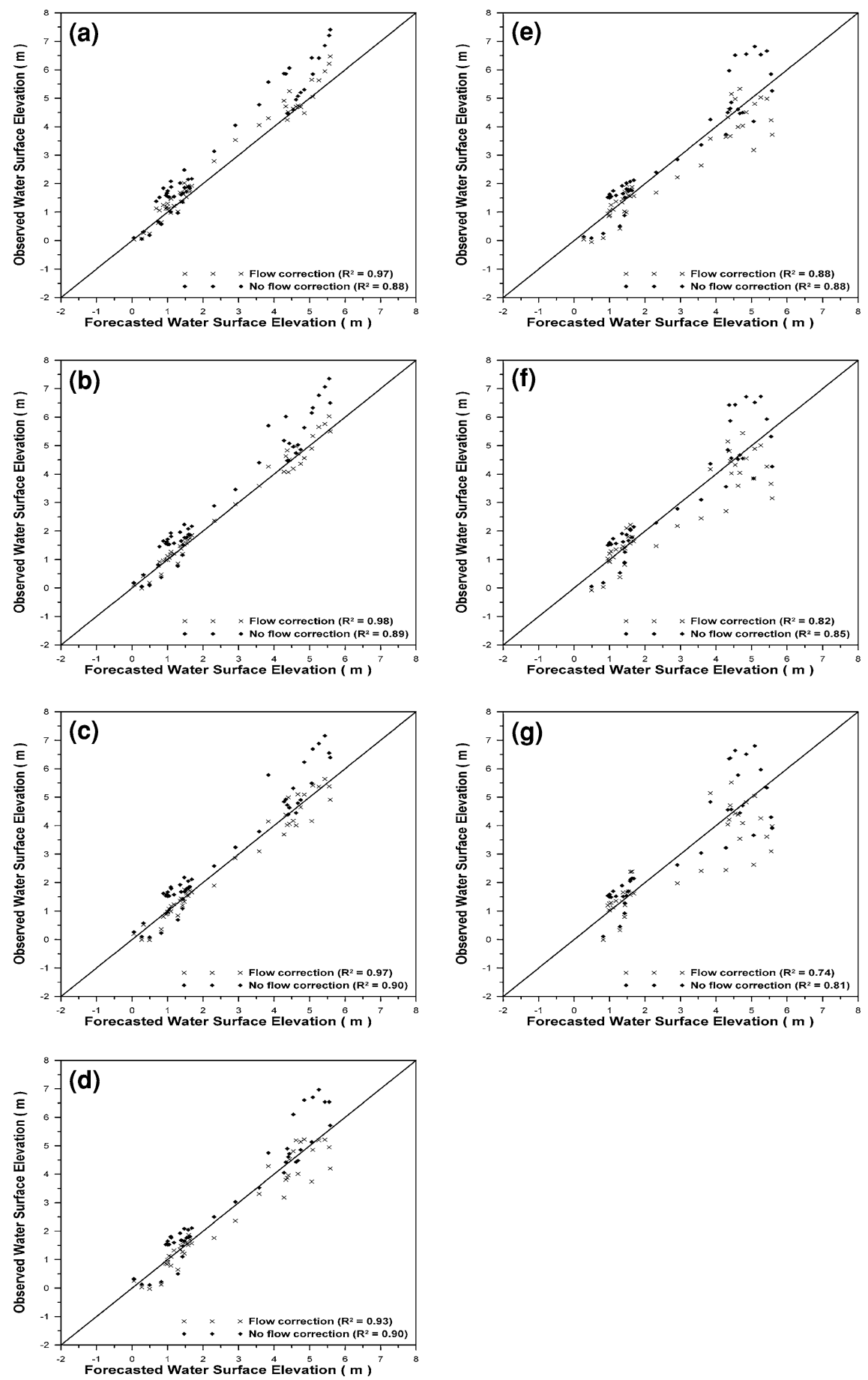

Fig. 6 Forecasted and observed water stages with and without discharge corrections at the Hsin-Hai Bridge during two typhoon events: a real time and $\mathbf{b}-\mathbf{g} 1-6 \mathrm{~h}$ forecast 
Method D Water stage correction based on the observed water stages at the seven stations to adjust the water stages at ungauge stations depended on the distances.

The spatial variations of water surface elevation along the Danshuei River-Tahan Stream forecasted for typhoons Bilis and Nari at 15th, 20th, and 25th h are presented in Fig. 7, which includes four different methods. It can be seen that the calculated water stage profiles approach the observed one if the methods $C$ and $D$ are adopted. The accuracy of water stage profiles is sufficient to provide the flood warning information for locations other than the gauge stations. In order to look into more detailed forecasting results, the temporal variation of water stage forecasting hydrographs are shown in Figs. 8 and 9 at Taipei Bridge and Hsin-Hai Bridge, respectively, for typhoon Nari, showing the current
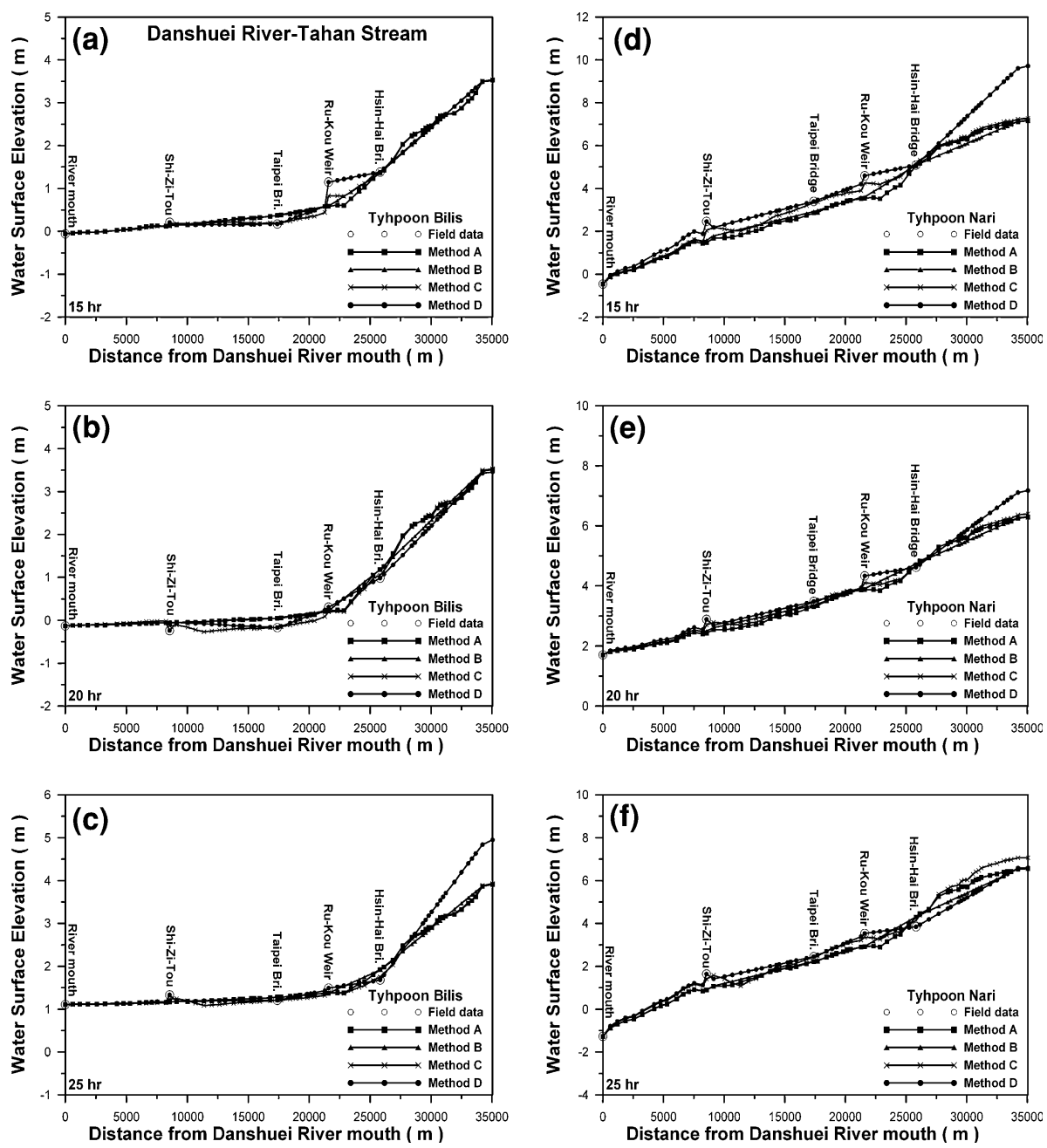

Fig. 7 Comparisons of observed and computed water stage profiles with four different water stage corrections for typhoon Bilis at time: (a) 15th hour; (b) 20th hour; and (c) 25th hour, and for typhoon Nari at time: (d) 15th hour; (e) 20th hour, and (f) 25th hour in the Danshuei River-Tahan Stream 

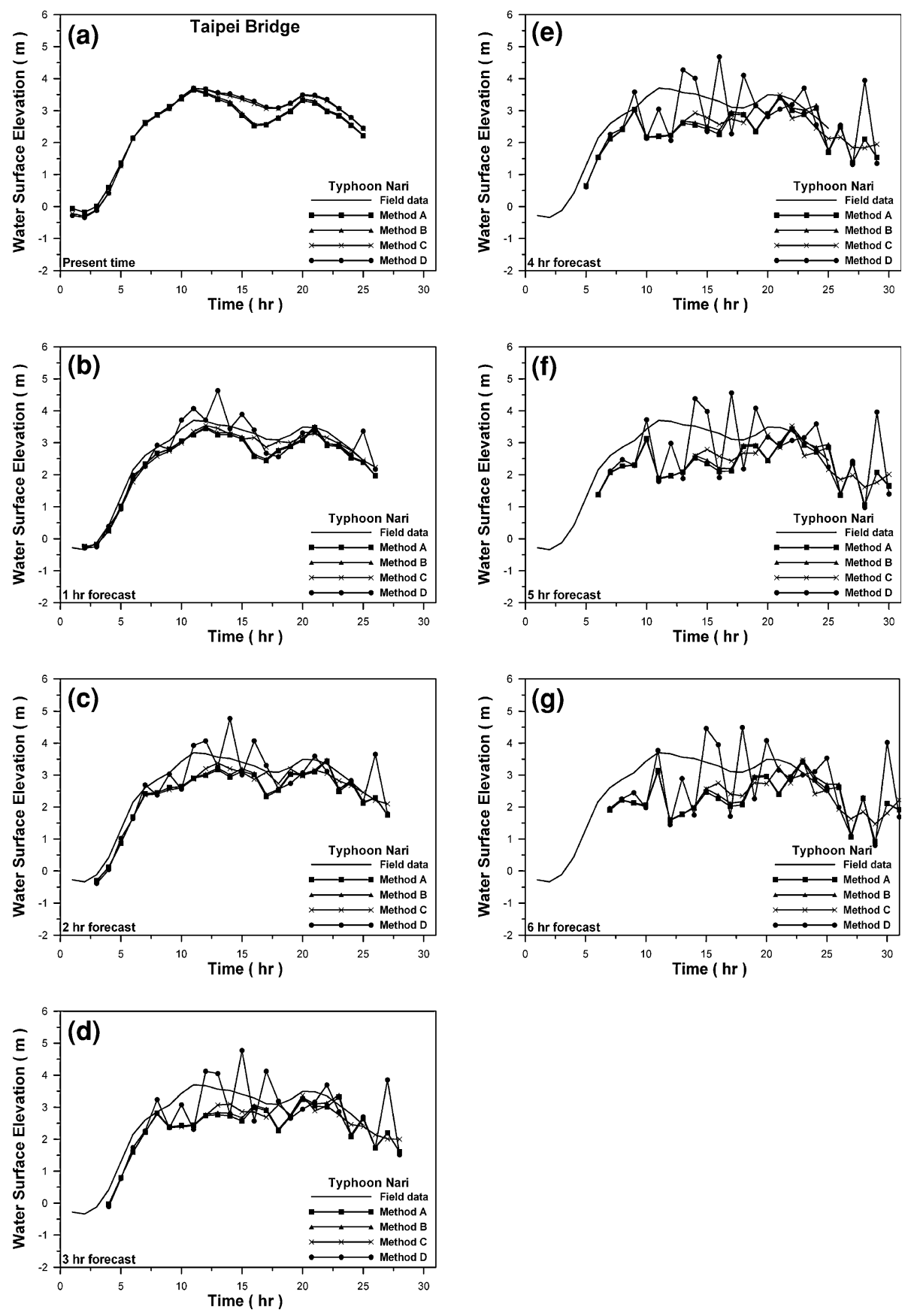

Fig. 8 a Present time and b-g 1-6 h forecasted water stage hydrographs with four different water stage corrections at the Taipei Bridge for typhoon Nari 

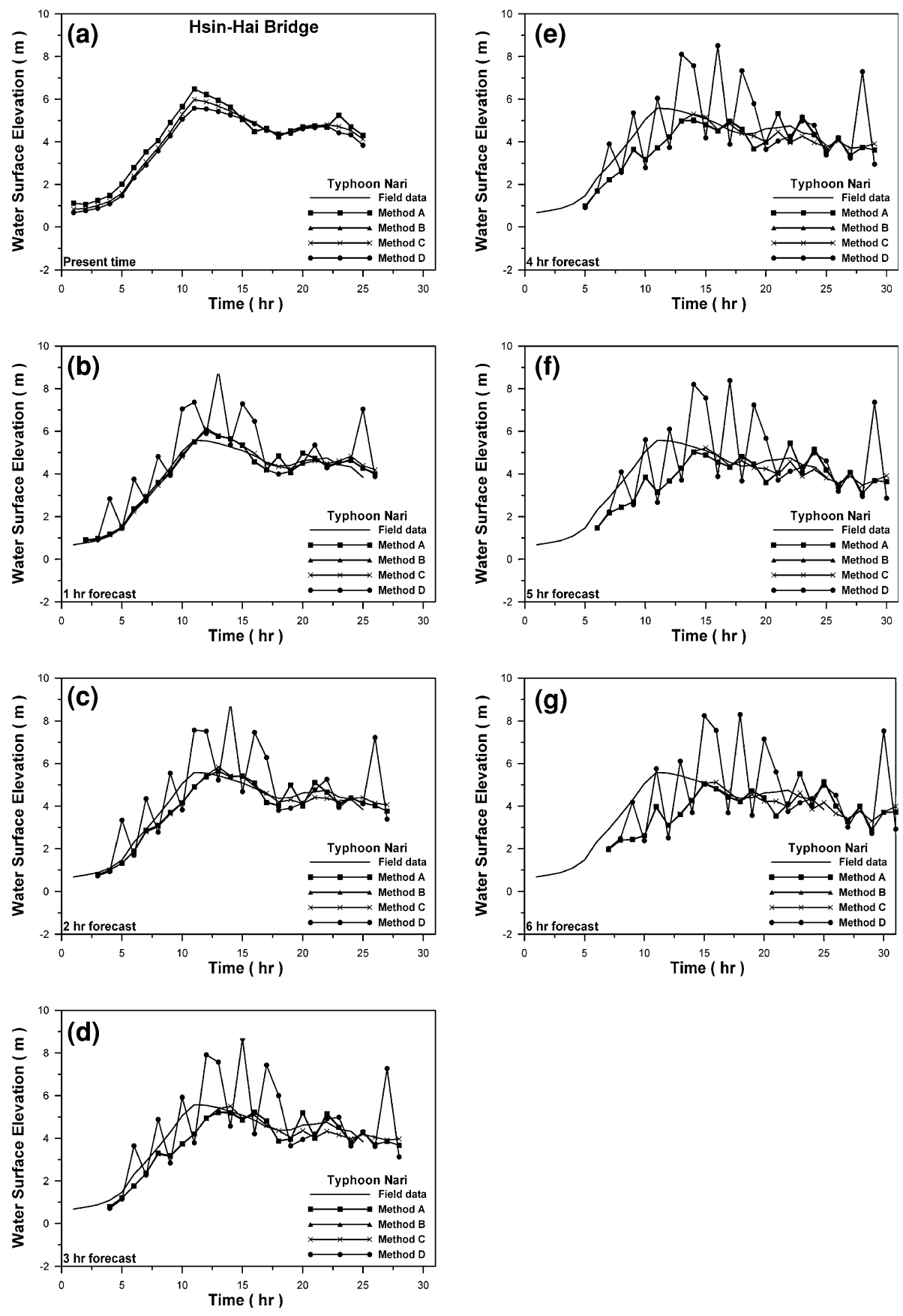

Fig. 9 a Present time and b-g 1-6 h forecasted water stage hydrographs with four different water stage corrections at the Hsin-Hai Bridge for typhoon Nari 

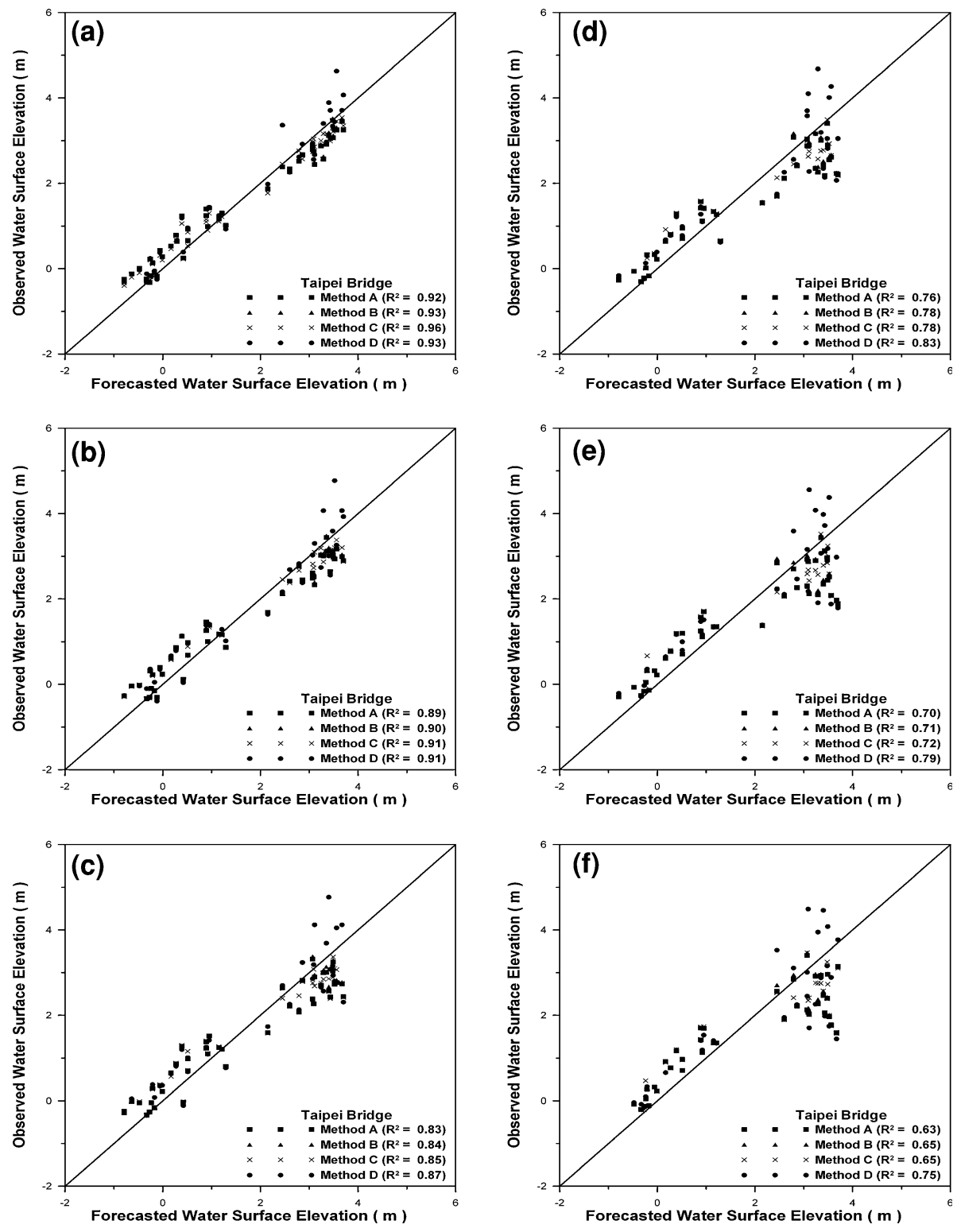

Fig. 10 Forecasted and observed water stages with four different water stage corrections at the Taipei Bridge for typhoon events (typhoons Bilis and Nari) a-f $1-6 \mathrm{~h}$ forecast

time and 1-6 h forecasting results. The calculated water stages for method D exhibits high fluctuation with time at Taipei Bridge and Hsin-Hai Bridge and results unsuitable for flood forecasting in the river system.

Scatter plots for point-by-point comparison of forecasted and observed water stage at the 1-6 h ahead for both typhoons Bilis and Nari at the Taipei Bridge and Hsin-Hai Bridge are presented in Figs. 10 and 11, respectively. The absolute mean and root-mean-square errors for the typhoons Bilis and Nari at $1-6 \mathrm{~h}$ forecast are also shown in Table 3. Through 

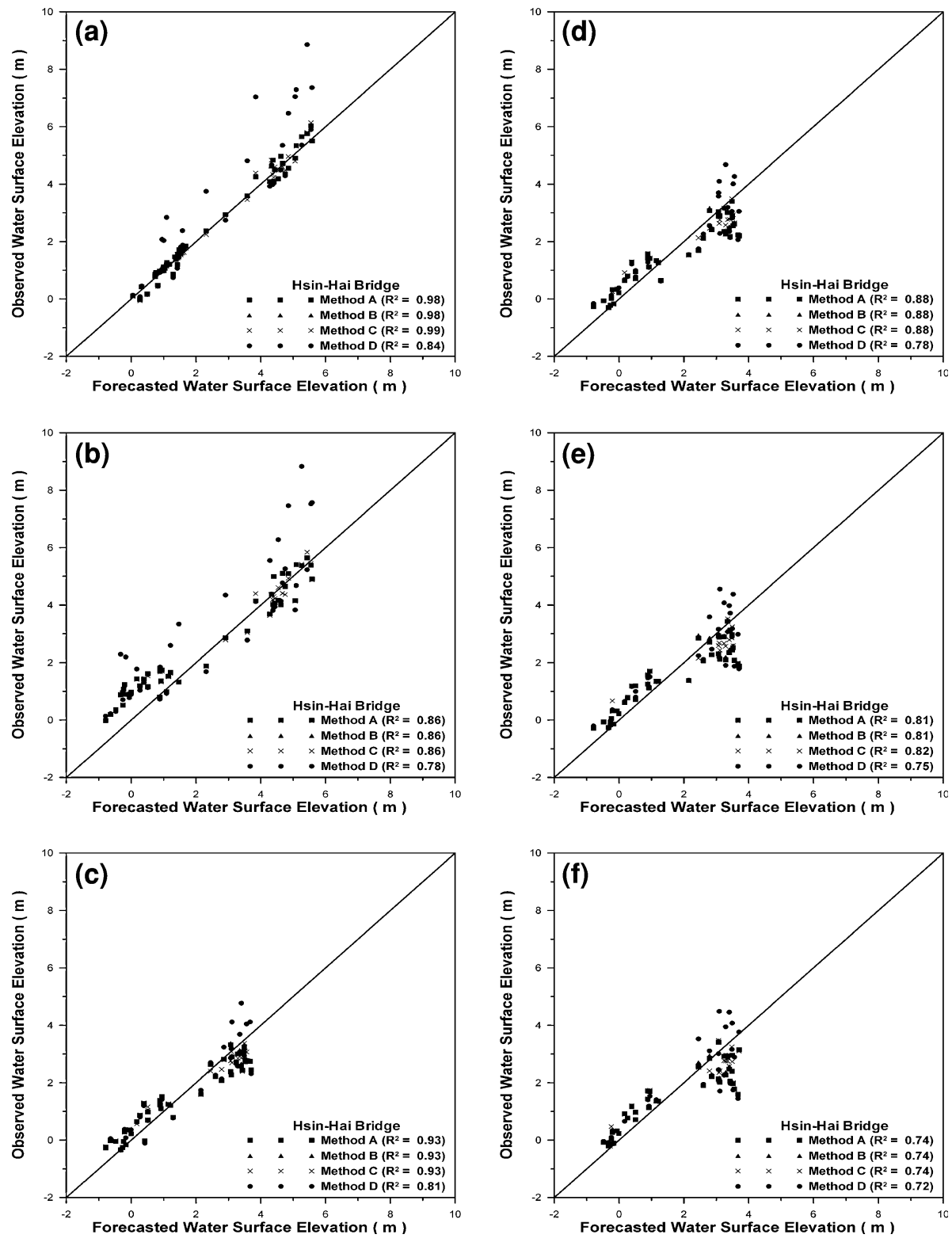

Fig. 11 Forecasted and observed water stages with four different water stage corrections at the Hsin-Hai Bridge for typhoon events (typhoons Bilis and Nari) a-f $1-6 \mathrm{~h}$ forecast

the overall evaluation, the results reveal that forecasting water stages at $1-6 \mathrm{~h}$ forecast with real-time stage correction (method $\mathrm{C}$ ) exhibits the best lead times. Table 3 illustrates that the absolute mean and root-mean-square errors of water stage increase with lead time (1-6 h). The accuracy for $1-3 \mathrm{~h}$ ahead is higher than that for $4-6 \mathrm{~h}$ ahead. It can be concluded that the flash flood forecasting in the river system is suitable for $1-3 \mathrm{~h}$ leading time only. 


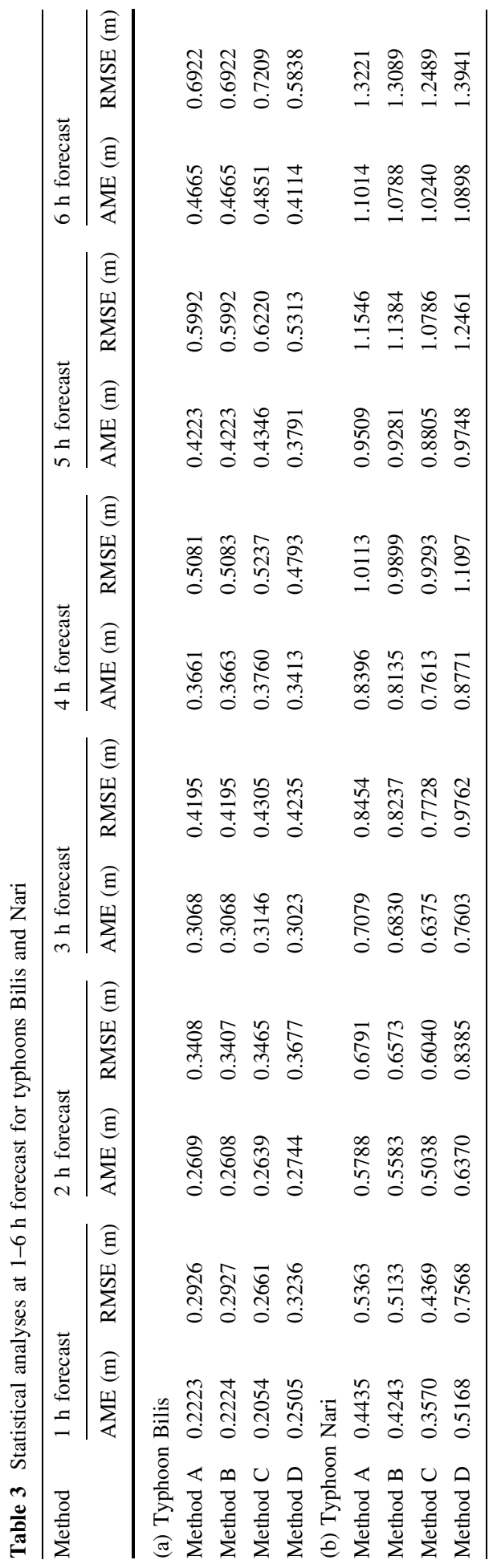




\section{Conclusions}

Accurate and reliable flow forecasting forms an important basis for efficient real-time management, including flood control, flood warning, reservoir operation, and river regulation. Flash flood forecasting is adopted to use the present-time flow to predict the advanced-time flow and provides the flood warning information. Based on the present-time flow, the advanced-time flow can be calculated to provide the water stage forecasting during the typhoon events. This study is based on the dynamic wave theory to develop a flood routing model for water stage forecasting. The developed model was applied to the Danshuei River system in northern Taiwan. Two typhoon events were adopted to validate and evaluate the model capability and availability.

First, the model was applied to validate and evaluate with and without discharge corrections at the Hsin-Hai Bridge (Tahan Stream), Chung-Cheng Bridge (Hsintien Stream), and Sir-Ho Bridge (Keelung River). The results reveal that the calculated water stage profiles approach the observed ones with and without discharge corrections. However, the water stage forecasting hydrograph with discharge correction is close to the observed water stage hydrograph and yields a better prediction than that without discharge correction. The model was then used to investigate the difference between the forecasting with different methods of real-time water stage correction when the discharge correction is included. Through the overall evaluation, the results reveal that forecasting water stages at $1-6 \mathrm{~h}$ forecast with real-time stage correction (method $\mathrm{C}$ ) exhibits the best lead times. The statistical analyses using absolute mean and root-mean-square errors of water stage increase with lead time. The accuracy for $1-3 \mathrm{~h}$ ahead is higher than that for $4-6 \mathrm{~h}$. It demonstrates that the flash flood forecasting in the river system is suitable for $1-3 \mathrm{~h}$ leading time only.

Acknowledgments The authors express their grateful appreciation for the sponsorship of the National Science Council of Taiwan under Grants NSC-95-2625-Z-239-002 and NSC-96-2625-Z-239-001. The measured data provided by Taiwan Water Resources Agency were also appreciated.

\section{References}

Acker P (1992) Hydraulic design of two-stage channels. In: Proceedings of the Institute of Civil Engineers, Waters and Maritime Engineering, vol 96, pp 247-257

Amein M, Fang CS (1970) Implicit flood routing in natural channel. J Hydraul Div ASCE 96(12):2481-2500

Babovic V, Canizares R, Jensen HR, Klinting A (2001) Neural networks as routine for error updating of numerical models. J Hydraul Eng 127(3):181-193. doi:10.1061/(ASCE)0733-9429(2001)127:3(181)

Hartnack J, Madsen H (2001) Data assimilation in river flow modelling. In: Proceedings of the fourth DHI software conference, Denmark

Hsu MH, Lin SH, Fu JC (2000) Flood forecast system model for Tanshui River basin. IV: Flood routing model. In: Hydroinformatics 2000 conference, University of Iowa, Iowa

Hsu MH, Fu JC, Liu WC (2006) Dynamic routing model with real-time roughness updating for flood forecasting. J Hydraul Eng 132(6):605-619. doi:10.1061/(ASCE)0733-9429(2006)132:6(605)

Kaya Y, Stewart M, Becker M (2005) Flood forecasting and flood warning in the Firth of Clyde, UK. Nat Hazards 36:257-271. doi:10.1007/s11069-004-4552-9

Khu ST, Liong SY, Babovic V, Madsen H, Muttil N (2001) Genetic programming and its application in real-time runoff forecasting. J Am Water Resour Assoc 37(2):439-451. doi:10.1111/j.1752-1688.2001.tb00980.x

Lamberti P, Pilati S (1996) Flood propagation models for real-time forecasting. J Hydrol (Amst) 175:239265. doi:10.1016/S0022-1694(96)80013-8

Lee TH, Hsu MH (2001) Maintenance and further development of flood forecasting system model for Tanshui River basin (II). Technical report, Water Resources Agency of the Ministry of Economic Affairs (in Chinese) 
Lee YH, Singh VP (1999) Tank model using Kalman filter. J Hydrol Eng 4:344-349. doi:10.1061/ (ASCE)1084-0699(1999)4:4(344)

Lee TH, Chang JL, Chiang CH, Tsai CH (2000) Flood forecast system model for Tanshui river basin. I: Climatology typhoon quantitative precipitation forecast model. In: Hydroinformatics 2000 conference, University of Iowa, Iowa

Liu WC, Hsu MH, Kuo AY (2001a) Investigation of long-term transport in Tanshui River estuary, Taiwan. J Waterw Port Coast Ocean Eng 127(2):61-71. doi:10.1061/(ASCE)0733-950X(2001)127:2(61)

Liu WC, Hsu MH, Kuo AY, Li MH (2001b) Influence of bathymetric changes on hydrodynamics and salt intrusion in estuarine system. J Am Water Resour As 37(5):1405-1416. doi:10.1111/j.1752-1688.2001. tb03648.x

Liu WC, Hsu MH, Wu CR, Wang CF, Kuo AY (2004) Modeling salt water intrusion in Tanshui River estuarine system—case-study contrasting now and then. J Hydraul Eng 130(9):849-859. doi:10.1061/ (ASCE)0733-9429(2004)130:9(849)

Liu WC, Chen WC, Cheng RT, Hsu MH, Kuo AY (2007) Modeling the influence of river discharge on salt intrusion and residual circulation in Danshuei River estuary, Taiwan. Cont Shelf Res 27:900-921. doi: 10.1016/j.csr.2006.12.005

Madsen H, Skotner C (2005) Adaptive state updating in real-time river flow forecasting: a combined filtering and error forecasting procedure. J Hydrol (Amst) 308:302-312. doi:10.1016/j.jhydrol.2004. 10.030

Madsen H, Butts MB, Khu ST, Ling SY (2000) Data assimilation in rainfall-runoff forecasting. Hydroinformatics 2000. In: Fourth international conference on hydroinformatics, Cedar Rapids, Iowa, USA, pp 23-27

Madsen H, Rosbjerg D, Damgard J, Hansen FS (2003) Data assimilation in the Mike 11 flood forecasting system using Kalman filter. In: Blöschl G (ed) Water resources systems-hydrological risk, management and development, IAHS publication no. 281, pp 75-81

Mu JB, Zhang XF (2007) Real-time flood forecasting method with 1-D unsteady flow model. China Ocean Eng 19:150-154

Nguyen QK, Kawano H (1995) Simultaneous solution for flood routing in channel networks. J Hydraul Eng 121(10):744-750. doi:10.1061/(ASCE)0733-9429(1995)121:10(744)

Preissman A (1961) Propagation of translatory waves in channels and rivers. In: Proceedings of 1st congress of French Association for Computation, Grenoble, France, pp 433-442

Refsgaard JC (1997) Validation and intercomparison of different updating procedures for real-time forecasting. Nord Hydrol 28:65-84

Saavedra I, Lopez JL, Garcia-Martinez R (2003) Dynamic wave study of flow in tidal channel system of San Juan River. J Hydraul Eng 129(7):519-526. doi:10.1061/(ASCE)0733-9429(2003)129:7(519)

Shiiba M, Laurenson X, Tachikawa Y (2000) Real-time stage and discharge estimation by a stochasticdynamic flood routing model. Hydrol Process 14:481-495. doi:10.1002/(SICI)1099-1085(20000228) $14: 3<481::$ AID-HYP950>3.0.CO;2-F

Wang RY, Hsieh LS (2000) Flood forecast system model for Tanshui River basin. II: Runoff forecast model. In: Hydroinformatics 2000 conference, University of Iowa, Iowa

WMO (1992) Simulation real-time intercomparison of hydrological models. Operational hydrology report no. 38. World Meteorological Organisation, Geneva

Yen CL, Lee TH, Wang RY, Young DL, Hsu MH (1998) Research and development of flood forecasting system model for Tanshui River Basin. Technical report, Water Resources Agency of the Ministry of Economic Affairs (in Chinese) 